\title{
Interactive comment on "Improved representation of river runoff in Estimating the Circulation and Climate of the Ocean Version 4 (ECCOv4) simulations: implementation, evaluation and impacts to coastal plume regions" by Yang Feng et al.
}

\section{Anonymous Referee \#2}

Received and published: 5 January 2021

The manuscript "Improved representation of river runoff in Estimating the Circulation and Climate of the Ocean Version 4 (ECCOv4) simulations: implementation, evaluation and impacts to coastal plume regions" by Feng et al. deals with an effort to improve the representation of river runoff in ECCOv4-based ocean simulations. For the purpose, the authors use both diffusive climatological runoff and daily point-source runoff to drive the river-related freshwater forcing in their simulations. Results from a series of experiments using different grid types and resolutions lead to detailed conclusions

Printer-friendly version

Discussion paper 
about the agreement between simulated and remotely-sensed sea surface salinity, and about the impacts on river plume area and volume, freshwater thickness and transport and mixed layer depth in the low- to mid-latitude ocean.

The topic, of a technical nature, is interesting and has direct impact on the modelling community. The manuscript is well written and structured and the figures presented back up the conclusions reached. I suggest acceptance after a moderate revision taking into account the following points.

My first criticism deals with the comparisons with observations. On one hand, the synchronized validation against SMAP SSS is done only over a period of 33 months. On the other hand, there is this discrepancy between using the WOA18 (including data from 1955-2010) and a climatology from the simulation based on only years 20152017. Could you please comment on the significance of such comparisons? Maybe emphasize the caveats in the text...

My second major concern: If I understood correctly, the difference between $\mathrm{C}$ and $\mathrm{R}$ runs is not only the forcing method (single point source versus area adjacent to river mouth) but also the temporal resolution of the prescribed runoff (monthly in $\mathrm{C}$ vs daily in R) and actually the dataset that serves as basis. That complicates the comparisons in my opinion and one is not sure if the improvements between $C$ and $R$ at a given resolution are entirely attributable to the forcing methodology (the benefit of which, I believe, is the point the authors are trying to make) or, on the other hand, additionally due to temporal resolution in the forcing. Please elaborate on this problem.

My last main question is: Why is there no simulation including the climatological forcing at the LLC540 resolution? Would make the comparisons more robust. The authors should also try to explain why the finest resolution seems to present a poorer comparison to observations.

Below some minor comments/corrections the authors should take into account in their revised version:

Printer-friendly version

Discussion paper
Interactive comment 
L44-46: Please explain in which sense are the results a benchmark?

L243: Should it read $-\mathrm{h}$ instead of $-\mathrm{H}$ ?

L306: Do you mean the negative bias is reduced?

L315-317: One sees only a slight tendency and mainly in the case of the Amazon river. I would be very careful in assuming that the interannual variability is reproduced, since it depends on many factors other than the prescribed runoff...

Figure 3: Why is LLC270C so much better than the other resolutions in the Amazon case?

Figure 5: What is the reason for the pronounced normalized bias increase from LLC270R to LLC540R?

Caption Figures S4 and S5: I believe you mean Columbia.

L443: "and responds".

L430: Caption of Figure 8 is wrong. I actually do not see the point of showing both area and volume. They do not differ much in the variability they present. I suggest presenting only volume.

L372: North Brazil Current and not Brazil Current.

L458: CO instead of CR.

Figure 10: Caption is incomplete.

L462: It is not clear how the transports were calculated. What do the authors mean by arc? I suggest completely removing the transport calculations from the discussion.

L540-543: I do not understand what is meant here. Increasing resolution always increases the richness of spatio-temporal scales!

Printer-friendly version

Discussion paper

Interactive comment on Geosci. Model Dev. Discuss., https://doi.org/10.5194/gmd-2020-321, 
2020.

GMDD

Interactive

comment 